\title{
Mental health and social security: the case of the Incapacity Benefit in Northern Ireland
}

\author{
Pauline M. Prior ${ }^{1}$ BSocSc, MSc(Econ), DPhil CQSW, Sinead McGilloway ${ }^{2}$, Stanley Herron ${ }^{2}$, Michael Donnelly ${ }^{2}$ \\ ${ }^{1}$ Department of Sociology and Social Policy, Queen's University, Belfast, Northern Ireland and ${ }^{2}$ Health and Health Care \\ Research Unit, Queens University, Belfast
}

\author{
Correspondence \\ Pauline M. Prior \\ Lecturer in Social Policy \\ Department of Sociology and \\ Social Policy \\ Queen's University \\ Belfast BT7 1NN \\ Northern Ireland \\ UK
}

\begin{abstract}
Although mental illness affects people from all income levels, a significant proportion of discharged psychiatric patients rely heavily on the benefit system. Therefore, changes in benefit entitlement are of great concern to these people who already find this system difficult to use. In the summer of 1995, using both focus groups and individual interviews, the views of 35 individuals with mental health problems and of five organizations involved in advocacy work were sought on the introduction of the Incapacity Benefit. These views raised serious questions about the extent to which the benefit system meets the needs of claimants with mental health problems, on the relevance of the models of disability used in sickness benefits, and on the impact of the Incapacity Benefit and the Job Seeker's Allowance on people with mental health problems and confirmed the need for further research.
\end{abstract}

Keywords: benefit, incapacity, mental health, mental illness, Northern Ireland, social security

Accepted for publication 10 December 1996

\section{Introduction}

The inter-relationship between poverty and mental illness is well documented. Research focuses either on poverty as a causal factor in the development and prolongation of the illness (Redlich 1958, Myers \& Bean 1968, Belle 1990, Hollingshead \& Thornicroft 1991) or as an effect of mental illness on the individual's employment pattern and earning power (Warr 1987, Meltzer et al. 1995). Whether a cause or an effect, the struggle to remain out of poverty remains a significant reality in the lives of people with mental health problems. Like other disabled people, many rely primarily on the benefit system for their income, and changes which involve further scrutiny of their socio-economic status, and a possible loss of benefit, cause intense anxiety. The introduction of the Incapacity Benefit in April 1995 (to replace Sickness and Invalidity Benefits) aroused particular concern within disability action groups not only because of the normal worries about possible confusion over new language and criteria of entitlement, but also because of the stated intention by
Government to reduce the rapidly increasing public expenditure on Invalidity Benefit (Reith \& Howard 1993, Lavery 1994, Short 1994, Girvan 1995).

The Incapacity Benefit is a single contributory benefit for people who are not able to work because of disability or ill health. Eligibility for the benefit is assessed on the basis on the 'own occupation test' during the first 28 weeks of the claim and the 'all work test' after this period. Whereas the first assesses the capacity of claimants to carry out their own occupation, the second assesses their capacity to perform a range of work related activities. Procedures for determining eligibility include the completion of a questionnaire by the claimant, a medical examination by the Benefits Agency Medical Service (known as the Medical Referee Service in Northern Ireland), a report, and a decision by an Adjudication Officer based on these. Those who are found capable of work and therefore not eligible for the benefit will then have to make a claim for the Jobseeker's Allowance introduced in October 1996. The latter replaces Unemployment Benefit and Income Support for people registered as 
unemployed, and includes much tougher conditions in relation to availability for work and actively seeking work.

Three areas of concern have been voiced by disability action groups. The first is that new claimants are entitled to less money under the new legislation, because of the loss of the Additional Pension (earnings related supplement), of the Age Allowance for women aged between 45 and 55 and men aged between 45 and 60, of the Dependent's Allowance for people under 60 and without children, and a lower level of benefit between the 28th and 52nd week (Short 1994, p. 15). The second is related to the cost-cutting thrust of the legislation. In 1994 research commissioned by the Department of Social Security into the factors affecting the growth in the number of people receiving longterm sickness benefits over the previous 14 years showed that there had been a rise of nearly one million, from 600000 in 1978/9 to 1.5 million in 1993/4 (DSS 1994, p. 33). Inevitably some people who have been receiving Invalidity Benefit for years will be regarded as 'capable of work' when tested against the new criteria. It was estimated that in the UK as a whole over 200000 people already in receipt of Invalidity Benefit would fail the new incapacity test and that, in addition, 95000 claimants would transfer from Incapacity Benefit to Unemployment Benefit or Income Support within the first year (Johnston 1995, p. 21). The third is concerned with the model of 'incapacity' used to assess an individual's ability to work. It appears to be completely contrary to current thinking which conceptualizes 'ablement' and 'disablement' as an effect of a combination of age, education, physical and mental attributes, rather than of a single physical or mental characteristic.

\section{Methods}

Within the context of these debates, a small project to examine consumers' views was carried out in May and June 1995. This was seen as a first step in a larger research project on poverty and mental health. Key informants in the five main organizations involved in advocacy work were interviewed to establish a baseline of information on the problems being brought to their attention by people with mental health problems (in relation to the Incapacity Benefit). These were the Northern Ireland Association for Mental Health, the Citizen's Advice Bureau, the National Schizophrenia Fellowship, Disability Action, the Belfast Law Centre. It was clear from these discussions that it was too early to assess the impact of the new benefit, but it was also clear that already it had aroused fear among actual and potential claimants.
In order to establish the reasons for this fear, it was decided to run three focus groups with people who had both mental health problems and experience of using the benefit system. The main conventions used in running focus groups were followed: the use of a topic guide, the encouragement of interaction between members and between members and the group leader, the taping and transcription of the discussion, and finally the use of a comfortable 'friendly' room and of circular seating arrangements. As the aim of the study was to explore areas of concern rather than to gather 'hard' information, the criteria for selection and the size of the groups were not controlled as strictly as recommended in the literature on focus groups (Zemke \& Kramlinger 1982, Morgan \& Spanish 1984, Basch 1987, Millward 1993, Fitzpatrick \& Boulton 1994, Kitzinger 1994).

The location of the groups and the organizations through which they were selected are as follows: Group 1 - National Schizophrenia Fellowship, Newry; Group 2 - Northern Ireland Association for Mental Health (NIAMH), Belfast; and Group 3 - Patient's Framework (Southern Health and Social Services Board and NIAMH), Dungannon. Because group participants were invited by a link person in each organization, the group size was not pre-determined. Although the ideal size is between 8 and 10, numbers varied - the Newry group had 10, the Belfast group 20 and the Dungannon group five participants. Because of the variation in size, the dynamics of the groups were quite different. However, similar concerns were raised by all. This article presents the most important of these within the context of the literature, interviews with advocacy organizations, and findings from two recent studies in Northern Ireland (McCoy \& Smith 1992, Donnelly et al. 1994,).

\section{Results and discussion}

Mental illness and battling with the benefit system: how to fight when you don't feel like fighting

Group participants were very clear about their views of the benefit system. They found information difficult to get, both on general benefit changes and on individual claims. This was particularly true in relation to benefits which were managed centrally from Castle Court in Belfast (sickness benefits). They also found that local social security office staff did not wish to deal with queries, the Freefone line was never available and answers to written queries were inadequate. All agreed that looking for information was extremely stressful, and was exacerbated by lack of control over ones own financial arrangements, negative or unhelpful attitudes of social security staff, and fear of loss or reduction of 
benefit. Some of the following comments provide more insight into the problems which they encountered.

There was a general lack of information. Many respondents considered that everything was shrouded in secrecy, for example 'we had to learn from the newspapers that Invalidity was being replaced by Incapacity we weren't told in a polite letter' and 'My book was running out and I didn't know what was happening next' and 'I've been told by my doctor that I have to go before a Board - nobody from the social security office told me directly' and 'My husband's benefit was cut by a large amount in the week (two weeks ago) and I don't know why ... my husband didn't eat for three days, he was so upset' and 'You don't know where you stand'. Some respondents felt that the policy of hiding information was deliberate: 'I believe it is government policy not to tell you' and 'One of the problems is that when you do get to know about a benefit they change the name and then you have to start the whole process again'.

Staff manner and general attitude were usually unhelpful. Some respondents had been 'completely ignored' and others found that staff did not really listen to changes in their circumstances - 'They don't listen to us ... I sent my new address to all the benefit offices and some are still not using it'. The unhelpful attitude was sometimes attributed to lack of understanding of mental illness - 'People with any sort of mental illness are out in the cold ... nobody wants them' and 'You feel very small ... they don't allow for people with mental health problems ....its as if the benefit officer is paying you out of his own pocket'.

On a positive note it was agreed that the appeal system was useful - all of the respondents in Newry and most of those in Dungannon and Belfast said they would appeal against a decision which involved a loss of benefit. Very few, however, would appeal for a second time. The discussion showed clearly that participants in this study perceived themselves as 'well' at the moment and that the decision to appeal or not to appeal might depend on the feeling of well-being at the time. Most people with mental health problems do not wish to put themselves under extra stress if this can be avoided. As Ann Davis pointed out in the recent workshop on social security and mental health, 'for periods of time people with mental health problems are unlikely to be able to meet the requirements made of claimants' (see Cobb 1993, Godfrey \& Saxton 1994 Zarb 1996, p. 26).

\section{Mental illness, employment and the benefit system}

One of the most consistent themes to emerge was that of the stigma attached to mental illness, particularly when seeking or keeping employment. If already in a job before falling ill, many people preferred to avoid labelling themselves in terms of their mental state because of the negative consequences which almost always followed. Individuals wished to maintain privacy about what were often very personal circumstances in the precipitation of the onset of mental illness. Furthermore, when a mental illness is disclosed, colleagues and employers often use the information negatively rather than positively. As one participant said It seems to be a social leprosy - having mental health problems'. Whilst acknowledging that mental illness affected their patterns of work, all group participants were very critical of employers who did not recognize that when not ill, their work could be as good as or better than that of their colleagues. They admitted that patterns of illness often disrupted work on an irregular basis and that this is difficult for employers. However, they felt that the benefit system should be more flexible to allow for periodic illness followed by a return to full capacity, in other words, that though mental health problems may be present all through the lives of some people this does not make them permanently incapable of working. Whilst acknowledging that some progress has been made in promoting flexibility, group members (some on Income Support and some on Incapacity Benefit) felt that the social security system has a long way to go in terms of promoting movement in and out of work. This theme was reiterated in the recent Social Security Advisory Committee (SSAC) workshop on mental health and the social security system, and underlined in a recent report from the London North committee for the Employment of People with Disabilities (Davoud 1996). It is clear to people who use the social security system, and to advocacy groups, that the system does not support the transition between claiming benefit and becoming established in employment (Zarb 1996, pp. 5 \& 29).

\section{The Incapacity Benefit: underlying assumptions or models of disability}

The new benefit has at its core the test of 'incapacity' for work, a test which will apply also to other sickness benefits in the future. The aim is to ensure that it will be targeted to people who are 'genuinely unable to work' because of their medical condition. In 1990, documentation from the DSS talked about incapacity in the following terms:

(It) tends to be used specifically to refer to someone's inability to work and to earn (and) most incapacity is temporary short-term sickness, leaving no continuing disability. Conversely, permanent disability need not necessarily mean permanent incapacity and certainly not total incapacity (DSS 1990, p. 14, par. 2.2). 
Participants in all three groups were shocked by the outmoded notion of disability which underlies the 'all work' test. The emphasis on physical functioning is unwelcome to those with physical as well as mental disabilities. For many years, wheelchair users and people with visual or hearing impairments have fought for the right to employment within the open job market. Under the new test, being in a wheelchair gives a score of 15 , which is sufficient in itself to qualify for the Incapacity Benefit. To claimants with mental health problems the higher score given to problems of physical functioning seems to undermine the serious impact of mental health problems on the ability to gain access to and stay in employment. The new test also ignores factors such as age, skills and experience in rendering one capable or incapable of work. Furthermore, it completely ignores the impact of disability on motivation and on opportunities. Participants in all three groups thought it more advantageous to emphasise physical disabilities on any self-assessment form. The advantage is two pronged - the requisite score might be reached on physical grounds alone and if unsuccessful, physical descriptions provide more concrete grounds for appeal.

Because of the anomalies which are evident in the methods of describing and scoring incapacity, one might be forgiven for thinking that the test was devised quickly and with very little thought or preparation. However, the Department of Social Security cannot be accused of lack of preparation or consultation in this case since the preparatory work took two years. In notes issued to doctors who would be involved in medical assessments, some of the consultation process was alluded to as follows:

It was important to involve a wide spectrum of expert opinion in the development of such new and complex assessment process - for example, disabled people, those who care for or represent them, doctors from a number of specialisms, such as general practice, occupational health and psychiatry, and academics (DSS 1994, Part 2, par. 1.5).

The aim of the development work was to design a functional test which would provide an effective assessment of incapacity for both single and combined disabilities and which could be applied to the majority of medical conditions (par. 1.4). The approach taken by the Office of Population Censuses and Surveys (OPCS) to the measurement of disability, i.e. deriving an overall score of disability from individual scores in 13 functional areas was the starting point, the experts clarified and ranked the descriptors within the functional areas, confirmed the point at which the effect of the medical condition affects the ability to work - the lower threshold, and the point at which the person should not be expected to work - the threshold for benefit (par. 1.9). All of the discussion was related not only to disability but to activities involved in the top 100 jobs in the UK economy (DSS 1995, par. 113). In spite of this intensive and wide ranging preparation, the result is not only flawed in terms of the underlying assumptions about capacity for work, but also in a number of specific areas some of which are highlighted below.

\section{Specific problems with the Incapacity Benefit}

One of the most frequent criticisms of the new benefit was the feeling that the definition of severe mental illness will be open to interpretation. If assessed as having a severe mental illness the claimant is entitled automatically to the benefit without any need for an interview by the Medical Referee Service (Benefits Agency Medical Services in GB). The criteria to be used include the nature of the psychological problem, the presence of such features as delusions or other psychotic symptoms, the treatment, and the type of supervision or care required (DSS 1995, par. 234). One of the essential features, the need for continued psychiatric care, sounds appropriate until one reads the range of care included in the definition. At the lower end of the spectrum is 'day care at least one day a week in a centre where qualified nursing care is available' (par. 233). Group participants pointed out that benefits are more easily accessed by those who are high users of care services, but that for many people with mental illnesses, attendance at day care conveys a public message which they wish to avoid. This view was confirmed at the SSAC workshop on social security and mental health where participants were 'concerned with what was perceived as the inappropriate medicalization of mental health' (Zarb 1996, p. 8).

Claimants and potential claimants of this benefit were extremely apprehensive about the possibility of having a medical interview. People who are not categorized as having a serious mental illness, fall into the 'mild or moderate' category and are assessed on the basis of a self assessment form. Though the claimant's main problem may be a mental health one, he or she is asked to fill in information about physical functioning and give a statement about mental condition. This and a doctor's letter are used by the Medical Referee Service to decide whether or not an interview with the claimant is necessary. Based on previous experiences of medical reviews of their benefits, group participants felt that even the possibility of being offered a medical interview would be sufficient to deter some people from claiming. The comments below describe the humiliation respondents experienced in previous encounters with the Medical Referee Service (known 
colloquially as the 'big doctor'). 'I'll never go through that again' and 'It was horrible, he never lifted his eyes, he just kept writing, he didn't seem to want to listen to me' and 'Some of them are there to put you off.' The decision as to whether or not a medical interview should be included in the claiming process is a difficult one, since the Royal College of Psychiatrists advised the Department of Social Security that an interview was more appropriate than a self assessment form for mental health problems. Doctors involved in the scheme are given special training and one hopes that, as a result of this training, applicants will feel less intimidated by the interview.

Another area of concern to research participants was the fact that mental disabilities attract lower scores than physical disabilities in the 'all work test'. This is a test designed to assess if the applicant is incapable of work. According to the briefing notes for medical assessors, the test assesses 'the effects of an individual's medical condition and the resultant disabilities upon that individual's capacity for all types of work' (DSS 1994, para. 1.2). Scores are attached to 15 functional activities on the basis of the claimant's ability to perform these activities and these scores are added together to give an overall score. The threshold score for benefit in one or all of these functional areas is 15 points. Mental health problems are also scored but on a lower scale. This is explained in the literature from the Department of Social Security as reflecting different methods of evaluating these functions and pointing out a lower threshold of eligibility (a score of 9 points) in the case of mental functioning than that in physical functioning or in a combination of both (a score of 15 points). This seems a plausible explanation in its own right, but when one realises that with a score of 5 points, for example, a person is deemed capable of working, individual scores are worth considering. An illustration of one such combination should clarify the point. A claimant who 'cannot look after himself without help from others' (2 points), for whom 'sleep problems interfere with his daytime activities' (1 point), and for whom 'concentration can only be achieved by prompting' (1 point), has acquired a total score of 4 points and has therefore failed to meet the required threshold for the benefit. To many mental health service users and to those involved in advocacy work with them, it seems ludicrous that anyone with this combination of problems could be seen as capable of holding down a job. In order to avoid any distress due to the possibility of not meeting the eligibility criteria on mental health grounds, participants in group discussions agreed that they would opt for physical symptoms whenever possible: in other words, they would emphasise these, even if the main reason for not working had nothing to do with physical functioning. The anomalies within the system of scoring in the 'all work test' have been brought to the attention of the Benefits Agency and are currently being examined (See Zarb, G. 1996).

The final issue raised by staff in the Belfast Law Centre and in the Bangor Citizens Advice Bureau, but not by focus group participants, was that of the new specification in relation to therapeutic earnings. Work of less than 16 hours a week may be allowed if it helps to improve, or to prevent or delay deterioration in the disease or bodily or mental disablement which causes (your) incapacity for work' (Paterson 1995, p. 63 quoting the regulations). If claimants are considered eligible for benefit on the grounds of physical incapacity, for example, but are doing work related to their mental state, this might be regarded as not therapeutic as it does not lead to an improvement of the incapacitating condition? Though some offices may interpret the law broadly, others may not do so.

\section{The potential recipients of Incapacity Benefit in Northern Ireland}

It was estimated in the most recent disability survey that there are 201000 disabled people in Northern Ireland. It was further estimated that of these 188000 live in private households and 13000 in some kind of communal establishment. Even among the most severely disabled, the majority live in private households relying therefore on themselves and on informal care networks to maintain a full quality of life (McCoy \& Smith 1992, para. 2.2) In comparison with Great Britain, Northern Ireland has a higher prevalence of disability, with 174 disabled people per 1000 of the population (with 20 per 1000 falling into the most severe category) in comparison with 142 per 1000 in Great Britain (para. 2.3).

Though the categorization developed by the OPCS and used in this survey includes two 'types of disability' which could cover most of the areas of difficulty experienced by people with mental illness - behaviour and intellectual functioning - the cases used to illustrate the levels of severity and methods of scoring do not represent mental illness adequately (McCoy \& Smith 1992, Appendix 4 quoting OPCS 1988, pp. 10-12). Working through this material confirmed our view of people with mental health problems as the most consistently invisible group in discussions on disability. We know from mental health statistics (hospital admissions and outpatient appointments) that approximately 7000 people currently use mental health services in Northern Ireland each year. Of course not all of these are disabled by their illness, but a significant proportion are. 
Perhaps an estimation of the potential population of disabled people is less helpful than an estimate based on existing claimants. In October 1994 there were 16757 people claiming Sickness Benefit, 70531 claiming Invalidity Benefit, and 14447 people claiming Severe Disability Allowance in Northern Ireland (Short 1994, p. 14). The proportion of claims on the grounds of mental illness is not known. Recent research by Hirst \& Sainsbury (1996, p. 13) estimated the prevalence of mental health problems among the Disability Living Allowance claimants studied as 12.8 percent. If, as was suggested at the Social Security Advisory Committee workshop on social security and mental health, the take-up of benefits is low among people with mental health problems (Zarb 1996), then it is clear that further research is needed to ascertain the extent of the problem. An examination of another study (Donnelly et al. 1994) yielded little in terms of data which might be useful in this discussion. By virtue of having a serious mental illness, all of the study participants satisfy the functional criteria for eligibility for Incapacity Benefit. Unsurprisingly, the majority of those studied rely on the social security system as their main source of income, only one third live independently, very few manage to get employment in the open market, and most get help in claiming benefits because of their continuing strong connections to the psychiatric system. This is a group of people who will have very little trouble in claiming the Incapacity Benefit.

\section{Concluding remarks}

One of the main problems with a study such as this is that it raises more questions that it answers. Therefore the conclusion is an agenda for research rather than definitive statements. A number of tentative conclusions can be drawn from this study and from the two most recent publications on mental health and the benefit system (Hirst \& Sainsbury 1996, Zarb 1996). Any change in the benefit system raises anxiety levels amongst claimants and this is particularly true for people with mental health problems. People with mental illnesses perceive themselves as having more problems than others in accessing both information on benefits and the actual benefits themselves. The Incapacity Benefit is perceived as being very problematic both by advocacy orgranizations and by consumers because it is based on an outmoded notion of disability; it is very cumbersome to use for both staff and claimants; many of the procedures and eligibility criteria are open to wide interpretation; the mental health interview is feared by claimants. Because it is easier to opt for a physical description of incapacity, the take-up from people with mental illnesses will be hard to monitor. As the Incapacity Benefit continues into its second year the need for further research on each of these issues is crucial.

\section{Acknowledgements}

My thanks to all those who helped in organizing group meetings and who participated in them, also to Patricia McEvoy and Roy Sainsbury for helpful advice.

\section{References}

Basch C. (1987) Focus group interview: an underutilized research technique for improving theory and practice in health education. Health Education Quarterly 14 (4), 411-448.

Belle D. (1990) Poverty and Women's Mental Health, American Psychologist, 45 (3), 385-389.

Davoud N. (1996) Welfare to Work: Disability Perspective, A report from the London North CEDP Incapacity Benefit Working Group, Committee for the Employment of People with Disabilities. CEDP, London.

Cobb A. (1993) Balancing the Payments? Social Security and Community Care for people who use Mental Health Services. MIND, London.

Donnelly M., Mc Gilloway S., Mays N., Perry S., Knapp M., Kavanagh S., Beecham J., Fenyo A. \& Astin J. (1994) Opening New Doors: An evaluation Of Community Care for People Discharged from Psychiatric and Mental Handicap Hospitals. HMSO, London.

Department of Social Security (1990) The Way Ahead: Benefits for Disabled People. Cm. 917, HMSO, London.

Department of Social Security (1994) The Medical Assessment of Incapacity Benefit. Benefits Agency, London.

Department of Social Security (1995) The Medical Advisers' Guide to Incapacity Benefit. Benefits Agency, London.

Fitzpatrick R. \& Boulton M. (1994) Qualitative methods for assessing health care. Quality in Health Care 3, 107-113.

Godfrey M. \& Saxton J. (1994) Helping People with Mental Health Problems Claim Disability Living Allowance, Working with Poverty Series, Paper 6. Department of Social Policy and Social Work, University of Birmingham.

Girvan J. (1995) Briefing Notes on the Incapacity Benefit. The Law Centre, Belfast.

Hollingshead A. \& Redlich F. (1958) Social Class and Mental Illness. John Wiley, New York.

Hirst M. \& Sainsbury R. (1996) Social Security and Mental Health: the Impact of Disability Living Allowance, SPRU Report 6. Social Policy Research Unit, University of York.

Johnston M. (1995) Qualms Before the Storm: an Overview of the New Incapacity Benefit and its Likely Impact, Frontline. Newsletter of the Belfast Law Centre, pp. 20-21 (Jan).

Kitzinger J. (1994) The methodology of focus groups: The importance of interaction between research participants. Sociology of Health and Illness 16 (1), 103-121.

Lavery M. (1994) Briefing Notes on the Incapacity Benefit. RADAR, London.

McCoy D. \& Smith M. (1992) The Prevalence of Disability Among Adults in Northern Ireland, Policy, Planning and Research Unit (PPRU), Surveys of Disability, Report 1. Department of Finance and Personnel, Belfast. 
Meltzer H., Gill B., Pettigrew M. \& Hinds K. (1995) Economic Activity and Social Functioning of Adults with Psychiatric Disorders. OPCS Surveys of Psychiatric Morbidity in Great Britain, Report 3. HMSO, London.

Millward L. (1993) Focus groups In G.M. Breakwell, S. Hammond \& C. Fye-Shaw (1993) Research Methods in Psychology, pp. 275-292. SAGE Publications, London.

Morgan D. \& Spanish M. (1984) Focus groups: a new tool for qualitative research. Qualitative Sociology 7 (3), 253-270.

Myers J. \& Bean L. (1968) A Decade Later: a Follow Up of Social Class and Mental Illness. John Wiley, New York.

OPCS (1988) The prevalence of disability among adults, Surveys of Disability in Great Britain, Report 1. HMSO, London.

Paterson J. (1995) Disability Rights Handbook: 20th Edn April 1995-April 1996. Disability Alliance Educational and Research Association, London.

Reith L. \& Howard M. (1993) Briefing notes on the Incapacity
Benefit. Disability Alliance Educational and Research Association, London.

Short, Aiden (1994) Incapacity Benefit: Revised Briefing 1.2, Disability Action, Belfast.

Silke D. (1993) Researching the DWA Self Assessment Form, DSS Research Report No. 13, HMSO, London.

Thornicroft G. (1991) Social deprivation and rates of treated mental disorder - developing statistical models to predict psychiatric service utilization. British Journal of Psychiatry 158, 475-484.

Warr P. (1987) Work, Unemployment and Mental Health. University Press, Oxford.

Zarb G (ed) (1996) Social Security and Mental Health: Report on the SSAC Workshop. Social Security Advisory Committee, Research Paper 7, HMSO, London.

Zemke R. \& Kramlinger T. (1982) Figuring Things Out: a Trainer's Guide to Needs and Task Analysis. Addison Wesley, Massachusetts. 